Article

\title{
The Interaction between Dietary Fiber and Fat and Risk of Colorectal Cancer in the Women's Health Initiative
}

Sandi L. Navarro ${ }^{1, *}$, Marian L. Neuhouser ${ }^{1,2}$, Ting-Yuan David Cheng ${ }^{3}$, Lesley F. Tinker ${ }^{1}$, James M. Shikany ${ }^{4}$, Linda Snetselaar ${ }^{5}$, Jessica A. Martinez ${ }^{6}$, Ikuko Kato ${ }^{7}$, Shirley A. A. Beresford ${ }^{1,2}$, Robert S. Chapkin ${ }^{8}$ and Johanna W. Lampe ${ }^{1,2}$

1 Division of Public Health Sciences, Fred Hutchinson Cancer Research Center, Seattle, WA 98109, USA; mneuhous@fredhutch.org (M.L.N.); ltinker@whi.org (L.F.T.); beresfrd@uw.edu (S.A.A.B.); jlampe@fredhutch.org (J.W.L.)

2 Department of Epidemiology, School of Public Health, University of Washington, Seattle, WA 98105, USA

3 Division of Cancer Prevention and Population Sciences, Roswell Park Cancer Institute, Buffalo, NY 14263, USA; david.cheng@roswellpark.org

4 Division of Preventive Medicine, University of Alabama at Birmingham, Birmingham, AL 35294, USA; jshikany@uabmc.edu

5 Department of Epidemiology, University of Iowa, Iowa City, IA 52242, USA; linda-snetselaar@uiowa.edu

6 Department of Nutritional Sciences, University of Arizona Cancer Center, Tucson, AZ 85724, USA; jam1@email.arizona.edu

7 Department of Oncology and Pathology, Wayne State University, Detroit, MI 48201, USA; katoi@karmanos.org

8 Program in Integrative Nutrition and Complex Diseases, Texas A\&M University, College Station, TX 77843, USA; r-chapkin@tamu.edu

* Correspondence: snavarro@fredhutch.org; Tel.: +1-206-667-6583

Received: 1 November 2016; Accepted: 25 November 2016; Published: 30 November 2016

\begin{abstract}
Combined intakes of specific dietary fiber and fat subtypes protect against colon cancer in animal models. We evaluated associations between self-reported individual and combinations of fiber (insoluble, soluble, and pectins, specifically) and fat (omega-6, omega-3, and docosahexaenoic acid (DHA) and eicosapentaenoic acid (EPA), specifically) and colorectal cancer (CRC) risk in the Women's Health Initiative prospective cohort $(n=134,017)$. During a mean 11.7 years (1993-2010), 1952 incident CRC cases were identified. Cox regression models computed multivariate adjusted hazard ratios to estimate the association between dietary factors and CRC risk. Assessing fiber and fat individually, there was a modest trend for lower CRC risk with increasing intakes of total and insoluble fiber ( $p$-trend 0.09 and 0.08). An interaction $(p=0.01)$ was observed between soluble fiber and DHA + EPA, with protective effects of DHA + EPA with lower intakes of soluble fiber and an attenuation at higher intakes, however this association was no longer significant after correction for multiple testing. These results suggest a modest protective effect of higher fiber intake on CRC risk, but not in combination with dietary fat subtypes. Given the robust results in preclinical models and mixed results in observational studies, controlled dietary interventions with standardized intakes are needed to better understand the interaction of specific fat and fiber subtypes on colon biology and ultimately CRC susceptibility in humans.
\end{abstract}

Keywords: butyrate; colorectal cancer; DHA; EPA; fat; fiber; omega-3; pectin

\section{Introduction}

Colorectal cancer (CRC) is the third most common type of cancer in the U.S., accounting for roughly $8 \%$ of new cancer cases and $8 \%$ of all cancer deaths in 2015 [1]. Lifestyle factors such as 
diet, physical activity, and body weight contribute substantially to CRC, and it is generally held that risk could be greatly reduced through dietary modification [2]. Dietary fiber and fat are two of the most well-studied dietary components in this regard [3]. Although many case-control studies have found inverse associations between fiber and fat intakes and CRC [4], data from epidemiologic studies are mixed [4-25], possibly due to differences in intake assessment, the type of fiber or fat analyzed, and residual confounding by other lifestyle and dietary factors. More recent studies have attempted to control for dietary confounders such as folate, alcohol, and red meat consumption, yet the contradictions in outcomes persist $[7,15,26,27]$. Finally, within the Women's Health Initiative (WHI) Dietary Modification Trial, a low fat dietary pattern intervention which included a focus on increasing servings of whole grains, vegetables, and fruits, was found to have no significant benefit on CRC incidence over an average of 8.1 years [28].

There is a growing recognition that dietary exposures are complex with synergistic and antagonistic effects between different dietary components contributing to chronic disease risk. Interactions between dietary constituents and microbial metabolites may also partially explain differences in population-level study outcomes $[29,30]$. In contrast to the equivocal data from observational studies in humans—in which each dietary component is evaluated separately—strong evidence for a combined effect of the subtypes of fat and fiber in relation to reduced colon tumorigenesis has been demonstrated in preclinical animal models [31-35]. Gut bacteria ferment dietary fiber (e.g., pectins, a type of fermentable soluble fiber) to butyrate [36-49], a potent histone deacetylase (HDAC) inhibitor [29,30] associated with reduced CRC risk [50-52]. Omega 6 (n-6) polyunsaturated fatty acids (PUFA), commonly found in refined vegetables oils, processed and fast foods, and red meat, typical in Western diets [53], and omega $3(n-3)$ PUFA in fish oils [54] are structural precursors of eicosanoids; those derived from n- 6 are mainly pro-inflammatory, whereas those produced from $n-3$ tend to have opposing effects [55,56]. Given the strong correlation between inflammation and CRC [56], higher intakes of long-chain $n$-3 PUFA provide biologic validity for a chemoprotective effect [57].

Preclinical research suggests that the combined effects of $n-3$ PUFA in fish oils (e.g., docosahexaenoic acid (DHA) and eicosapentaenoic acid (EPA)) and butyrate from fermentable fiber (e.g., pectin) may work in concert to enhance the chemopreventive potential of either dietary component alone, primarily by increasing apoptosis [31,33,34,58-62]. While other factors, such as low dietary intakes of fiber and certain fatty acid subtypes, may contribute to the mixed results in humans, the lack of evaluation of the interaction between subtypes of dietary fat and fiber, i.e., pectins in soluble fiber and marine-derived $n-3$ PUFA, may also explain why the chemoprotective effects of fiber and fat have not been consistently detected in prospective cohort studies. Therefore, our objectives for this study were to determine the associations between the individual and combinations of subtypes of fiber (soluble, and pectins specifically, which leads to the production of butyrate, vs. insoluble) and fat $(n-3$, and DHA + EPA, specifically, vs. $n-6)$, and risk of CRC in the WHI.

\section{Materials and Methods}

\subsection{Study Population}

The WHI is a large prospective study focused on understanding preventive strategies for major chronic diseases in postmenopausal women [63]. WHI includes both a multi-component randomized Clinical Trial (CT) and an Observational Study (OS). The CT $(n=68,132)$ was actually three overlapping randomized controlled trials evaluating combined hormone therapy or estrogen alone versus placebo (HRT), a low-fat dietary pattern versus comparison (Dietary Modification), and calcium and vitamin D supplementation versus placebo $(\mathrm{CaD})$, on the risk of breast and colorectal cancers, coronary heart disease, and osteoporotic fractures. The OS $(n=93,676)$ examines a broader range of lifestyle, health, and risk factors and risk of common chronic diseases in postmenopausal women initially interested in but ineligible for one or more of the clinical trials. Postmenopausal women aged 50-79 years were recruited from the general population at 40 different Clinical Centers between 1993 and 1998, 
with trial follow-up information and outcome data available through 2005, and post-trial follow-up information and outcome data for these analyses available through September, 2010, the end of the first WHI Extension Study. All participants in the CT and OS were included in the present analysis except women who were randomized to the intervention arm of the Dietary Modification trial ( $n=19,541)$. Further details on recruitment, study design, and baseline measures have been published elsewhere [63-66]. Institutional review board approval was obtained from all clinical sites, and women provided written informed consent prior to participation and for follow-up in the Extension period. The WHI ClinicalTrials.gov identifier is NCT00000611.

\subsection{Data Collection and Dietary Assessment}

Detailed information on demographic characteristics, medical, reproductive and familial CRC history, and lifestyle factors were collected at baseline. Weight and height were assessed with a standardized protocol using a calibrated balance beam scale and stadiometer, respectively, and body mass index (BMI) was computed as weight in $\mathrm{kg} /$ height in $\mathrm{m}^{2}$. Physical activity was assessed by computing average weekly metabolic equivalents of moderate and vigorous leisure-time physical activity.

Dietary intake over the past three months was measured from the WHI food frequency questionnaire (FFQ) [67] using a standardized protocol at baseline for all women, and at year one for Dietary Modification CT participants. Follow-up FFQs were completed in years two through nine for a rotating proportion (33\%) of Dietary Modification CT participants. The baseline FFQ data were used for the current study. The FFQs contained 122 food and food group items, and 19 adjustment questions, the majority of which ask about food practices pertaining to types and amounts of added fats (e.g., fat added at the table and in cooking), and three summary questions on food purchasing and preparation methods [67]. The WHI nutrient database was derived from Nutrition Data Systems for Research (NDS-R, version 2005, Nutrition Coordinating Center, University of Minnesota, Minneapolis, MN, USA). The database has over 140 nutrient values including total fat, total PUFA, $n-6$ and n-3 PUFA, total DHA and EPA from food sources; and total, insoluble and soluble fiber, and pectins.

\subsection{Colorectal Cancer Case Ascertainment}

Clinical outcomes, including cancer diagnoses, were updated annually in the OS and semi-annually in the CT until 2005 when the outcomes were thereafter reported annually using mail or telephone questionnaires. Self-reports of CRC were verified by trained physician adjudicators at the Clinical Centers who reviewed medical records and pathology reports [68]. All CRC diagnoses were then confirmed by blinded review at the WHI Clinical Coordinating Center at the Fred Hutchinson Cancer Research Center.

\subsection{Statistical Analysis}

Exclusions were made for women who reported history of colon or rectal cancers prior to baseline enrollment or who were missing these data $(n=946)$. Further exclusions were made for women with FFQs containing incomplete information, or data that suggested biologically implausible daily energy intakes of $<2512$ or $>20,930 \mathrm{~kJ}(n=4649)$, or extreme BMIs $\left(<15\right.$ or $\left.>50 \mathrm{~kg} / \mathrm{m}^{2} ; n=2069\right)$. Finally, women who were missing data for smoking, physical activity, and education variables combined $(n=9)$, or were lost to follow up $(n=577)$, were excluded, leaving a sample of 134,017 for analysis.

Cox proportional hazards models were used to estimate hazard ratios (HR) and 95\% confidence intervals (95\% CI) for the association of fiber (total, insoluble, soluble, and pectins) and fat (total, n-6, $n-3$, and DHA + EPA) intakes and CRC risk. Dietary variables were evaluated as separate main effects, as quintiles of intake, using the lowest quintile as the reference group. Quintile assignments of dietary variables from the baseline FFQ were calculated based on the distribution in non-cases. Tests for trend were performed in a separate Cox model treating quintiles 1-5 as linear. Fat variables were analyzed both as $g$ intake/day with energy adjusted in the models, and as \% energy. As the results 
for both were similar (data not shown) we present only fat as $g$ intake/day. Interactions (a total of seven determined a priori: total fat $\times$ total fiber; insoluble fiber $\times n-6$ PUFA; soluble fiber $\times n-3$ PUFA; insoluble fiber $\times n-3$ PUFA; soluble fiber $\times$ DHA + EPA; pectins $\times n-3$ PUFA; pectins $\times$ DHA + EPA) were assessed by adding the multiplicative interaction term between linear quintiles of dietary fat and fiber variables to the final multivariate model. For the significant interaction of soluble fiber and DHA + EPA, post-hoc HRs and 95\% CIs were computed for each quintile comparison for each of the 25 fat $\times$ fiber groups.

All models were adjusted for established or suggestive risk factors for CRC: (age (years, continuous); family history of CRC (yes/no); red and processed meat consumption (g/day, continuous); BMI (kg/ $\mathrm{m}^{2}$, continuous); leisure physical activity (total metabolic equivalent- $\mathrm{h} /$ week, continuous); smoking (current or past/never); alcohol use (g/day, continuous); current use of non-steroidal anti-inflammatory drugs (NSAIDs; yes/no); folate (food plus supplements; $\mu$ g dietary folate equivalents/day, continuous); calcium (food plus supplements; mg/day; continuous)) [69,70], and confounders that altered point estimates for dietary outcome measures by more than $10 \%$ : total energy intake (kcal/day, continuous); history of screening colonoscopy (yes/no); education level (high school; technical school or some college; college grad or post); ever use of menopausal hormones (yes/no); and study component (OS, CT) and CT randomization assignment (HRT, Dietary Modification or $\mathrm{CaD})$. We created a "missing" category for covariates with data missing for $<0.5 \%$ of the participant population (NSAIDs, $n=91$, smoking, $n=1737$, education level, $n=1005$, and colonoscopy screening, $n=4736)$, and imputed the median values for physical activity ( $n=5230)$ to reduce the number of participants who would be dropped from the analysis. All tests for individual dietary factors were two sided and statistical significance was set at $p<0.05$. Tests for interaction were adjusted for multiple testing using Bonferroni correction $(0.05 / 7$ tests conducted $=p<0.007)$. All analyses were conducted using Stata (v14.1; StataCorp, College Station, TX, USA).

\section{Results}

The distribution of baseline participant characteristics and dietary intake for CRC cases and non-cases are given in Table 1. During a mean follow up of 11.7 years ( \pm 3.5 ; range: $0.02-17.5$ years), a total of 1952 CRC cases were reported. Women with CRC appeared less likely to have ever used hormone therapy and consumed less calcium. Intakes of all other dietary variables were very similar in cases and non-cases.

Table 1. Baseline characteristics, colorectal cancer risk factors, and dietary constituents for participants in the Women's Health Initiative 1993-2010 ${ }^{1}$.

\begin{tabular}{ccc}
\hline Characteristic & Cases $(\boldsymbol{n = 1 9 5 2 )}$ & Non-Cases $(\boldsymbol{n}=\mathbf{1 3 2 , 0 6 5 )}$ \\
\hline Age, (years) & $66(6.9)$ & $63(7.3)$ \\
Height $(\mathrm{cm})$ & $162(6.3)$ & $162(6.4)$ \\
Body mass index $\left(\mathrm{kg} / \mathrm{m}^{2}\right)$ & $28(5.7)$ & $28(5.5)$ \\
White & Race $(\%)$ & 84 \\
Black & 85 & 8 \\
Other/Unknown ${ }^{2}$ & 9 & 8 \\
Education (\% college graduate) & 6 & 40 \\
Screening colonoscopy (\%) & 38 & 51 \\
Family history of CRC (\%) & 49 & 15 \\
NSAID (\% current use) & 19 & 19 \\
Alcohol use at baseline (g/day) & 17 & $5(10.8)$ \\
Never smokers (\%) & $5(11.3)$ & 50 \\
Physical activity (MET-h/week) & 49 & $13(13.7)$ \\
Ever used post-menopausal Hormone therapy (\%) & $12(12.6)$ & 56 \\
Total energy (kJ/day) & 48 & \\
Total fiber (g/day) & Dietary intake & $6787(2642)$ \\
Soluble fiber (g/day) & $6766(2671)$ & $16(6.9)$ \\
Pectins (g/day) & $16(6.9)$ & $4.3(1.8)$ \\
Insoluble fiber (g/day) & $4.3(1.8)$ & $2.5(1.2)$ \\
& $2.5(1.2)$ & $11.8(5.1)$ \\
\hline
\end{tabular}


Table 1. Cont.

\begin{tabular}{ccc}
\hline Characteristic & Cases $(\boldsymbol{n}=\mathbf{1 9 5 2})$ & Non-Cases $(\boldsymbol{n}=\mathbf{1 3 2 , 0 6 5 )}$ \\
\hline Total fat (g/day) & $60(32.7)$ & $59(32.0)$ \\
$n-3$ (g/day) & $1.41(0.8)$ & $1.41(0.8)$ \\
DHA + EPA (g/day) & $0.12(0.12)$ & $0.13(0.12)$ \\
$n-6$ (g/day) & $10.8(6.2)$ & $10.7(6.2)$ \\
Linoleic acid (g/day) & $10.8(6.2)$ & $10.7(6.1)$ \\
Linolenic acid (g/day) & $1.3(0.7)$ & $1.3(0.7)$ \\
Calcium (mg/day) & $803(439)$ & $827(453)$ \\
Folate (DFE, $\mu$ g/day) & $478(206)$ & $488(207)$ \\
Red meat (g/day) & $0.69(0.57)$ & $0.67(0.55)$ \\
\hline
\end{tabular}

${ }^{1}$ Means (Standard Deviation) unless otherwise specified; ${ }^{2}$ Includes Hispanic, American Indian, Asian/Pacific Islander, Mixed races, and Refused; ${ }^{3}$ Total metabolic equivalent-hours/week. CRC, colorectal cancer; DFE, dietary folate equivalents; DHA, docosahexaenoic acid; EPA, eicosapentaenoic acid; NSAIDs, non-steroidal anti-inflammatory drugs.

Table 2 provides data on associations of total, insoluble, and soluble fiber, and pectins, with CRC risk. When assessing fiber as a main effect, higher versus lower total soluble and insoluble fibers were associated with modest, but non-significant lower risk of CRC. There was a suggestion of inverse linear trends for total and insoluble fiber, ( $p$-trend $=0.09$ for total fiber; $p$-trend $=0.08$ for insoluble fiber).

Table 2. Multivariate-adjusted hazard ratios and 95\% CIs for the association of fiber with colorectal cancer in the Women's Health Initiative $(n=134,017)$ 1993-2010.

\begin{tabular}{|c|c|c|c|}
\hline Quintiles of Dietary Intake & No. Cases & Person-Years & Multivariate Adjusted HR $(95 \% \text { CI })^{1}$ \\
\hline \multicolumn{4}{|c|}{ Total fiber (g/day) } \\
\hline$<10.3$ & 420 & 302,828 & 1.00 (Reference) \\
\hline $10.3-13.6$ & 426 & 312,546 & $1.00(0.87,1.15)$ \\
\hline $13.6-17.0$ & 354 & 316,244 & $0.83(0.71,0.97)$ \\
\hline $17.0-21.5$ & 372 & 318,893 & $0.87(0.74,1.03)$ \\
\hline$>21.5$ & 380 & 318,844 & $0.90(0.73,1.10)$ \\
\hline$p$-trend & & & 0.09 \\
\hline \multicolumn{4}{|c|}{ Soluble fiber (g/day) } \\
\hline$<2.8$ & 408 & 304,051 & 1.00 (Reference) \\
\hline $2.8-3.7$ & 409 & 312,599 & $0.97(0.84,1.12)$ \\
\hline $3.7-4.6$ & 361 & 316,928 & $0.85(0.73,1.00)$ \\
\hline $4.6-5.8$ & 410 & 318,628 & $0.96(0.81,1.13)$ \\
\hline$>5.8$ & 364 & 317,148 & $0.84(0.69,1.03)$ \\
\hline$p$-trend & & & 0.14 \\
\hline \multicolumn{4}{|c|}{ Insoluble fiber (g/day) } \\
\hline$<7.4$ & 433 & 302,242 & 1.00 (Reference) \\
\hline $7.4-9.8$ & 413 & 312,804 & $0.93(0.81,1.07)$ \\
\hline $9.8-12.3$ & 357 & 316,721 & $0.81(0.69,0.94)$ \\
\hline $12.3-15.7$ & 370 & 318,704 & $0.84(0.72,1.00)$ \\
\hline$>15.7$ & 379 & 318,884 & $0.87(0.72,1.06)$ \\
\hline$p$-trend & & & 0.08 \\
\hline \multicolumn{4}{|c|}{ Pectin (g/day) } \\
\hline$<1.4$ & 399 & 303,832 & 1.00 (Reference) \\
\hline $1.4-2.0$ & 397 & 313,746 & $0.97(0.84,1.12)$ \\
\hline $2.0-2.6$ & 379 & 316,302 & $0.92(0.79,1.06)$ \\
\hline $2.6-3.5$ & 396 & 318,847 & $0.97(0.83,1.13)$ \\
\hline$>3.5$ & 381 & 316,626 & $0.94(0.80,1.11)$ \\
\hline p-trend & & & 0.56 \\
\hline
\end{tabular}

1 The following variables were included in both the multivariate and continuous models: total energy intake (continuous), age (continuous), body mass index (continuous), education (high school, technical school or some college, college graduate or post-graduate), family history of colorectal cancer (yes/no), history of colonoscopy (yes/no), current NSAID use (yes/no), alcohol intake (continuous), smoking history (never, former, current), physical activity (total metabolic equivalent-hours, continuous), ever use of hormone therapy (never, current/former), folate (DFE; $\mu \mathrm{g} /$ day, continuous), calcium (mg/day, continuous), and red meat intake (g/day, continuous), and study component (OS, CT) and CT randomization assignment and treatment arm. OS, observational study; CT, clinical trial; DFE, dietary folate equivalents; NSAIDs, non-steroidal anti-inflammatory drugs. 
The associations of total fat, n-6 PUFA, n-3 PUFA, and EPA + DHA with CRC risk were null with most HRs near the null value of 1.0 (Table 3 ).

Table 3. Multivariate-adjusted hazard ratios and 95\% CIs for the association of fat with colorectal cancer in the Women's Health Initiative $(n=134,017)$ 1993-2010.

\begin{tabular}{|c|c|c|c|}
\hline Quintiles of Dietary Intake & No. Cases & Person-Years & Multivariate Adjusted HR $(95 \% \text { CI })^{1}$ \\
\hline \multicolumn{4}{|c|}{ Total fat (g/day) } \\
\hline$<33.1$ & 345 & 309,005 & 1.00 (Reference) \\
\hline $33.1-45.6$ & 432 & 318,884 & $1.20(1.04,1.39)$ \\
\hline $45.6-59.7$ & 394 & 316,808 & $1.05(0.90,1.24)$ \\
\hline $59.7-80.6$ & 381 & 316,629 & $0.98(0.82,1.18)$ \\
\hline$>80.6$ & 400 & 313,067 & $0.98(0.76,1.27)$ \\
\hline$p$-trend & & & 0.44 \\
\hline \multicolumn{4}{|c|}{ n-6 PUFA (g/day) } \\
\hline$<5.9$ & 375 & 309,046 & 1.00 (Reference) \\
\hline $5.9-8.1$ & 405 & 314,292 & $1.02(0.88,1.18)$ \\
\hline $8.1-10.7$ & 390 & 316,554 & $0.95(0.81,1.11)$ \\
\hline $10.7-14.6$ & 394 & 317,021 & $0.92(0.78,1.09)$ \\
\hline$>14.6$ & 388 & 312,441 & $0.84(0.68,1.05)$ \\
\hline p-trend & & & 0.10 \\
\hline \multicolumn{4}{|c|}{ n-3 PUFA (g/day) } \\
\hline$<0.80$ & 401 & 308,532 & 1.00 (Reference) \\
\hline $0.80-1.09$ & 389 & 314,521 & $0.94(0.82,1.08)$ \\
\hline $1.09-1.41$ & 383 & 316,931 & $0.90(0.78,1.05)$ \\
\hline $1.41-1.90$ & 377 & 316,759 & $0.87(0.75,1.03)$ \\
\hline$>1.90$ & 402 & 312,611 & $0.90(0.74,1.09)$ \\
\hline$p$-trend & & & 0.16 \\
\hline \multicolumn{4}{|c|}{ DHA + EPA (g/day) } \\
\hline$<0.04$ & 402 & 307,408 & 1.00 (Reference) \\
\hline $0.04-0.07$ & 389 & 312,402 & $0.97(0.84,1.12)$ \\
\hline $0.07-0.11$ & 393 & 315,998 & $0.98(0.85,1.13)$ \\
\hline $0.11-0.18$ & 389 & 318,148 & $0.99(0.85,1.14)$ \\
\hline$>0.18$ & 379 & 315,397 & $0.98(0.84,1.13)$ \\
\hline p-trend & & & 0.87 \\
\hline
\end{tabular}

1 The following variables were included in both the multivariate and continuous models: total energy intake (continuous), age (continuous), body mass index (continuous), education (high school, technical school or some college, college graduate or post-graduate), family history of colorectal cancer (yes/no), history of colonoscopy (yes/no), current NSAID use (yes/no), alcohol intake (continuous), smoking history (never, former, current), physical activity (total metabolic equivalent-hours, continuous), ever use of hormone therapy (never, current/former), folate (DFE $\mu \mathrm{g} /$ day, continuous), calcium ( $\mathrm{mg} /$ day, continuous), and red meat intake (g/day, continuous), and study component (OS, CT) and CT randomization assignment and treatment arm. OS, observational study; CT, clinical trial; DFE, dietary folate equivalents; DHA, docosahexaenoic acid; EPA, eicosapentaenoic acid; NSAIDs, non-steroidal anti-inflammatory drugs. PUFA, polyunsaturated fatty acids.

We next examined the interaction of fat and fiber subtypes in relation to CRC risk. The interaction between DHA + EPA and soluble fiber was statistically significant $(p$-interaction $=0.01)$, with a significant decreased risk of CRC with increasing DHA + EPA intake among those in the lowest quintile of soluble fiber intake ( $p$-trend $=0.02$; Table 4 ) and a borderline increased risk of CRC with increasing DHA + EPA among those in the highest quintile of soluble fiber ( $p$-trend $=0.07$; Table 4$)$. There was a marginal statistically significant association between pectins and DHA + EPA $(p=0.05)$, with a similar pattern of attenuation, whereby the protective effects of higher intakes of pectins were no longer apparent with higher intakes of DHA + EPA (data not shown). However, these interactions were no longer significant when adjusted for multiple comparisons. There were no other significant interactions between the various dietary fiber and fat combinations. 
Table 4. Soluble fiber and DHA + EPA stratified by quintile of intake, and association with colorectal cancer in the Women's Health Initiative $(n=134,017)$ 1993-2010.

\begin{tabular}{|c|c|c|c|c|c|c|c|c|}
\hline & & \multicolumn{5}{|c|}{ DHA + EPA (g/Day) } & \multirow[t]{2}{*}{ HR $(95 \% \text { CI })^{1}$} & \multirow[t]{2}{*}{$p$-Trend ${ }^{2}$} \\
\hline \multirow{6}{*}{$\begin{array}{l}\text { Soluble fiber } \\
\text { (g/day) }\end{array}$} & & Q1 & Q2 & Q3 & Q4 & Q5 & & \\
\hline & Q1 & $\begin{array}{c}1.00 \\
(\operatorname{Ref})^{3}\end{array}$ & $\begin{array}{c}0.88 \\
(0.68,1.13)\end{array}$ & $\begin{array}{c}0.78 \\
(0.59,1.04)\end{array}$ & $\begin{array}{c}0.88 \\
(0.65,1.20)\end{array}$ & $\begin{array}{c}0.59 \\
(0.40,0.88)\end{array}$ & $\begin{array}{c}0.91 \\
(0.84,0.98)\end{array}$ & 0.02 \\
\hline & Q2 & $\begin{array}{c}0.81 \\
(0.62,1.06) \\
\end{array}$ & $\begin{array}{c}0.82 \\
(0.63,1.07) \\
\end{array}$ & $\begin{array}{c}0.91 \\
(0.70,1.18) \\
\end{array}$ & $\begin{array}{c}0.80 \\
(0.60,1.06) \\
\end{array}$ & $\begin{array}{c}0.91 \\
(0.69,1.23) \\
\end{array}$ & $\begin{array}{c}1.03 \\
(0.96,1.11) \\
\end{array}$ & 0.44 \\
\hline & Q3 & $\begin{array}{c}0.71 \\
(0.53,0.96)\end{array}$ & $\begin{array}{c}0.84 \\
(0.63,1.11)\end{array}$ & $\begin{array}{c}0.73 \\
(0.55,0.97)\end{array}$ & $\begin{array}{c}0.65 \\
(0.48,0.87)\end{array}$ & $\begin{array}{c}0.79 \\
(0.59,1.06)\end{array}$ & $\begin{array}{c}0.99 \\
(0.91,1.06)\end{array}$ & 0.70 \\
\hline & Q4 & $\begin{array}{c}0.76 \\
(0.56,1.05)\end{array}$ & $\begin{array}{c}0.86 \\
(0.65,1.15)\end{array}$ & $\begin{array}{c}0.87 \\
(0.66,1.15)\end{array}$ & $\begin{array}{c}0.90 \\
(0.68,1.18)\end{array}$ & $\begin{array}{c}0.77 \\
(0.57,1.02)\end{array}$ & $\begin{array}{c}1.00 \\
(0.93,1.07)\end{array}$ & 0.96 \\
\hline & Q5 & $\begin{array}{c}0.70 \\
(0.49,1.01) \\
\end{array}$ & $\begin{array}{c}0.53 \\
(0.37,0.78) \\
\end{array}$ & $\begin{array}{c}0.73 \\
(0.53,1.00) \\
\end{array}$ & $\begin{array}{c}0.81 \\
(0.60,1.08) \\
\end{array}$ & $\begin{array}{c}0.80 \\
(0.60,1.08) \\
\end{array}$ & $\begin{array}{c}1.08 \\
(1.00,1.17) \\
\end{array}$ & 0.07 \\
\hline \multicolumn{2}{|c|}{$\operatorname{HR}(95 \% \mathrm{CI})^{1}$} & $\begin{array}{c}0.97 \\
(0.89,1.08)\end{array}$ & $\begin{array}{c}0.90 \\
(0.81,1.00)\end{array}$ & $\begin{array}{c}1.02 \\
(0.92,1.13)\end{array}$ & $\begin{array}{c}0.99 \\
(0.89,1.09)\end{array}$ & $\begin{array}{c}1.00 \\
(0.89,1.11)\end{array}$ & & \\
\hline \multicolumn{2}{|c|}{$p$-trend ${ }^{2}$} & 0.62 & 0.05 & 0.72 & 0.80 & 0.95 & & \\
\hline
\end{tabular}

${ }^{1} \mathrm{HR}$ and $95 \% \mathrm{CI}$ across quintiles of soluble fiber and DHA + EPA; ${ }^{2} p$-trend values from linear interactions across each row and column. The following variables were included in the model: total energy intake (continuous), age (continuous), body mass index (continuous), education (high school, technical school or some college, college graduate or post-graduate), family history of colorectal cancer (yes/no), history of colonoscopy (yes/no), current NSAID use (yes/no), alcohol intake (continuous), smoking history (never, former, current), physical activity (total metabolic equivalent-hours, continuous), ever use of hormone therapy (never, current/former), folate ( $\mu \mathrm{g} /$ day, continuous), calcium (mg/day, continuous), and red meat intake (g/day, continuous), and study component (OS, CT) and CT randomization assignment and treatment arm; ${ }^{3}$ the combination of the first quintiles for soluble fiber and DHA + EPA is the reference group for all comparisons within quintiles. OS, observational study; CT, clinical trial; DFE, dietary folate equivalents; DHA, docosahexaenoic acid; EPA, eicosapentaenoic acid; NSAIDs, non-steroidal anti-inflammatory drugs. PUFA, polyunsaturated fatty acids.

\section{Discussion}

The results of the present analysis in a large, prospective cohort of postmenopausal women do not support the results obtained in preclinical studies demonstrating that combinations of higher fiber and fat subtypes are associated with reduced risk of CRC. While there was a modest additional protective effect of either dietary component when intake of the other was low, this protective effect was attenuated with greater consumption in our study population. Intakes and ranges were very low such that only women in the highest quintile of fiber were consuming adequate intakes for this age group ( $21 \mathrm{~g} /$ day for women ages 51-70 years), with a very small percentage consuming high intakes [71]. Further, intakes of $n-3$ PUFA, and DHA and EPA, specifically, were substantially lower than the levels used in experimental diets. These factors may have prevented detection of an association.

It is generally thought that CRC risk could be reduced through dietary modification, including increased dietary fiber intake and reduced fat intake [3]. Dietary fiber mainly includes remnants of plant foods resistant to digestion by human enzymes and therefore arrives in the colon relatively intact, where it undergoes metabolism by gut microbiota. In the 2011 Colorectal Cancer Report, part of the Continuous Update Project, the World Cancer Research Fund/American Institute for Cancer Research Expert Panel classified evidence supporting consumption of fiber-containing foods and CRC protection as 'convincing' [72], noting that for every $10 \mathrm{~g} /$ day increase in fiber, there was a $10 \%$ decrease in CRC risk. Mechanisms hypothesized to explain how dietary fiber may reduce CRC include increased stool bulk and reduced intestinal transit time, resulting in reduced exposure to potential carcinogens; decreased secondary bile acids and subsequent generation of reactive oxygen species; and fiber fermentation by gut microbiota to short-chain fatty acids, particularly butyrate [73-75]. It is now well-documented that butyrate induces apoptosis in tumor cells through inhibition of HDAC and subsequent activation of the Fas receptor-mediated extrinsic death pathway [31,76-79]. Given the potential importance of fiber fermentation on CRC risk, consideration of fiber subtypes may be important; however, few studies have examined fiber subtype (i.e., soluble and insoluble, 
or more and less fermentable), and associations are similar, with both null $[9,10]$ and inverse associations [80-83] reported.

When evaluating total fiber and subtypes in the present study, CRC risk was reduced for all quintiles of increased consumption and a marginal linear trend was observed; however, most quintiles did not reach statistical significance. Inconsistencies across epidemiologic studies may be attributed in part to lower overall fiber intakes and narrow ranges of fiber intakes in Western populations which reduce statistical power [13]. Mean fiber intake in the U.S. is $~ 15 \mathrm{~g} /$ day [4]. Intakes at or above current recommended intakes ( $25 \mathrm{~g} /$ day for women and $38 \mathrm{~g} /$ day for men) [71] show robust protection against CRC with relative risks ranging from 0.72 to $0.90[4,6,26]$. Only $10 \%$ of our study population reported intakes of dietary fiber $>25 \mathrm{~g}$ /day, thus our ability to detect a protective effect was compromised.

Overlaying the conflicting data observed with dietary fiber and CRC is a similar body of inconsistent literature on the association between subtypes of fat, particularly $n-3$ PUFA, and CRC risk. In addition to the anti-inflammatory effects promulgated by changes in the eicosanoid milieu, other putative actions of $n-3$ PUFA have been proposed. These include alterations in membrane fluidity and lipid raft composition, which may affect receptor signaling involved in proliferation and apoptosis [84], and modulation of oxidative stress [57,85]. As with dietary fiber, laboratory data consistently show reduced CRC risk with marine $n$-3 PUFA [58], while epidemiologic data are less convincing. Whereas two meta-analyses reported reduced CRC risk with $n$-3 PUFA from fish intake [86,87], two systematic reviews concluded that there is insufficient [15] or limited [7] evidence to suggest an association between long-chain $n$ - 3 PUFA intake and CRC risk. A more recent publication reported no overall association between $n-3$ PUFA and CRC risk among 123,529 individuals; however, among women in the same cohort, $n$-3 PUFA intake after CRC diagnosis had a protective effect on survival [88].

In the WHI population, we did not observe an association between any dietary fat subtypes and CRC risk. As with fiber, intakes of $n-3$ PUFA were very low; mean intakes were $1.4 \mathrm{~g} /$ day (range 0.1-10.4) for $n-3$, and 0.04 and $0.08 \mathrm{~g}$ /day (range 0-1.4 and 0-3.1, respectively) for EPA and DHA. While specific recommendations for $n-3$ PUFA intake have not been determined, the Food and Nutrition Board of the Institute of Medicine established adequate intake levels for alpha-linolenic acid (ALA), the precursor of long-chain $n$-3 PUFA, of $1.1 \mathrm{~g} /$ day for women over the age of 19 [71]. Only about half of our study population had intakes at that level. Furthermore, the Academy of Nutrition and Dietetics recommends a minimum intake of $0.5 \mathrm{~g} /$ day of combined EPA and DHA [89]. Less than $2 \%$ of the women in our study cohort reached an intake level above $0.5 \mathrm{~g} /$ day.

Despite the inconsistent epidemiologic data for dietary fiber and fat, studies in preclinical animal models have shown that combinations of fiber and fat work synergistically to protect against colon cancer [58-62]. In a series of experiments, the effects of different types of fat (fish oil or corn oil; $15 \mathrm{~g} / 100 \mathrm{~g}$ ) and fiber (pectin or cellulose; $6 \mathrm{~g} / 100 \mathrm{~g}$ ) diets were tested on tumorigenesis and various other aspects of colonocyte physiology $[58,90]$. Both fish oil and pectin alone, relative to corn oil and cellulose feeding, resulted in a significantly lower proportion of animals with adenocarcinomas; however, the combination of fish oil and pectin led to an even greater reduction [58]. Additional work showed changes to the re-dox environment within rat colonocytes with a concomitant reduction in DNA damage $[35,59,91]$. Serving as the primary energy source for colonic epithelial cells, butyrate induces cellular reactive oxygen species (ROS) generation, creating a pro-oxidant environment [31]. At the same time, long chain $n$-3 PUFA from fish oil (e.g., DHA) incorporated into cell membranes, are susceptible to oxidation due to their high degree of unsaturation [33]. These physiological attributes of butyrate and DHA are relevant as lipid peroxidation can directly trigger the release of pro-apoptotic factors from mitochondria into the cytosol, through a p53-independent, calcium-mediated cell death pathway [33]. Given that butyrate independently induces apoptosis through an extrinsic, HDAC inhibition-mediated pathway, the combination of dietary constituents, and subsequent effects on intrinsic apoptotic pathways, would be expected to exponentially increase apoptosis.

Dietary fiber and fatty acids, in combination, and risk of CRC in humans has only recently begun to be evaluated. In a large cohort study $(n=96,354)$ of Seventh Day Adventists, risk of CRC was 
reduced by $22 \%$ among all vegetarians combined compared to non-vegetarians, but protection was greatest among pescovegetarians who consume high amounts of both fiber and $n-3$ PUFA-containing fish (HR: 0.57; 95\% CI: 0.40, 0.82) [92]. Furthermore, striking reciprocal changes in gut mucosal cancer risk biomarkers, the microbiome, and the metabolome were reported after African Americans were given a high-fiber (primarily in the form of resistant starch, including pectin), low-fat diet and rural Africans were given a high-fat, low-fiber Western-style diet [93]. Significantly increased butyrate production and suppressed secondary bile acid synthesis were also noted after the diet exchange to high-fiber, low-fat intake in African Americans [93].

An analysis in the Rotterdam prospective cohort $(n=4967)$ lends support to the hypothesis that higher intakes of fat and fiber are an important factor mediating the relationship between these dietary variables. An increased risk of CRC was observed with $n$-3 PUFA intake and dietary fiber intakes below the median, but not when fiber intakes were above [22]. It is noteworthy that the levels of fiber intakes were markedly lower (mean $26 \mathrm{~g} /$ day) relative to the intakes among pescovegetarians in the Seventh Day Adventist population (mean $40 \mathrm{~g} /$ day) and the African American intervention participants (mean $55 \mathrm{~g} /$ day), but higher than the intakes in our population (mean $16 \mathrm{~g} /$ day). Adding to the complexity of the relationship, when evaluated by food sources of $n-3$ PUFA in the Rotterdam study, increased CRC risk was restricted to intake from non-marine sources which contain ALA; there was no association when $n$-3 PUFA from marine-derived (e.g., EPA and DHA) sources were evaluated [22]. Contrary to these results, evaluation by $n-3$ PUFA source in a case-control study did not show any difference between non-marine and marine sources and interaction with dietary fiber. In this instance, greater protection of $n$-3 PUFA was found among individuals with lower dietary fiber intakes although overall intake was low (median $18.6 \mathrm{~g} /$ day) [94], consistent with our observation of the significant reduced risk of CRC among women with the lowest soluble fiber and highest DHA + EPA intakes. The authors speculated that high fiber intake may interfere with lipid absorption, offsetting potential beneficial effects of certain fatty acids [94].

While intakes in animal models do not directly translate to human intakes, the amount of fiber and fat used in preclinical experiments is comparable, as a proportion of intake, to what is currently recommended for humans. For example, the amount of fiber in the rat diets was $6 \%$ by weight, which is approximately equivalent to $30 \mathrm{~g} /$ day for humans [58]. This level of intake was only approached in the highest quintile of total fiber intake ( $>21.5 \mathrm{~g} /$ day). Similarly, all rat diets contained fat at $15 \%$ by weight and $30 \%$ of energy, with fish oil comprising approximately $1 \%-5 \%$ [58]. Women in WHI consumed $33 \%$ of their calories from fat on average, but less than $1 \%$ from $n-3$ PUFA and even less from combined DHA and EPA from fish oil (highest quintile $>0.18 \mathrm{~g} /$ day). In the VITamins And Lifestyle (VITAL) cohort $(n=68,109)$, individuals using fish oil supplements on $4+$ days/week for $3+$ years experienced $49 \%$ lower $C R C$ risk than non-users ( $\mathrm{HR}=0.51,95 \% \mathrm{CI}=0.26-1.00 ; p$-trend $=0.06$ ) [17]. An average serving of oily fish (e.g., salmon or mackerel) provides 1.5-3 g of marine fish oil [95]. Thus, it may be difficult to achieve the levels of $n-3$ PUFA needed for a chemoprotective effect through diet alone.

Strengths of this study include the large, well-characterized prospective cohort. As CRC was one of the primary outcomes of WHI, incident cases were expertly adjudicated and confirmed. Additionally, detailed information was collected on a wide range of exposures, including diet, with reliability subsequently assessed [65]. Finally, this is the largest prospective cohort to evaluate the interactions of subtypes of fiber and fat on CRC to date.

As with all observational studies, there are limitations. First, we relied on self-report via FFQ to capture usual dietary intake, therefore we cannot rule out measurement error. FFQs are subject to lack of precision and inaccurate recall of dietary intake [96]. As dietary intakes were only assessed at baseline, it is possible that diets changed over time. However, we performed a sensitivity analysis using FFQ from women in the Dietary Modification comparison arm (the only group for which FFQ data from multiple time-points were collected) between years $0,1,3,6$, and 9, and found that correlations were 0.62 for fiber intake and 0.44 for total fat intake, suggesting that intake remained relatively stable during the follow-up. The WHI FFQ has been shown to yield nutrient estimates that are similar to 
those obtained from short-term dietary recall and recording methods, and test-retest reliability for most nutrients was high (e.g., FFQ estimates for total, saturated, and polyunsaturated fat variables were all within $10 \%$ of those from food records and $24-\mathrm{h}$ recalls, although dietary fiber was slightly higher $\sim 17 \%$, and information on fat and fiber subtypes was not evaluated) [67]. Our fiber exposure also did not include the integration of dietary fiber supplement use, which is known to be higher with age and among women [97]. Lastly, measurement of the level of EPA/DHA incorporation in plasma or the tissue level was not conducted. It is widely known that the biological activities of these compounds depend on their bioavailability [98] and FFQ estimates only provide a surrogate for exposure.

Finally, while we adjusted for several potential confounders, we did not directly evaluate antioxidant content of the diet. Because the combination of butyrate and $n-3$ PUFA drive apoptosis via an oxidative-dependent mechanism, higher antioxidant intakes might antagonize this protective effect. In addition, there is some evidence that high antioxidants promote CRC in both preclinical [59,91] and epidemiologic [99-101] studies. Although mean intakes for several individual nutrients with antioxidant capacity (e.g., vitamins C, E, and beta-carotene) were very similar between cases and controls at baseline ( $<1 \%$ difference), total antioxidant capacity of dietary intakes was not considered.

\section{Conclusions}

In summary, at the levels of dietary intake consumed by women in WHI, we did not find evidence of a protective association between increased subtypes of fiber and fat intakes in combination, and reduced risk of CRC. Our results for fat and fiber separately are in agreement with what has been reported previously, namely modest inverse associations with fiber, but no consistent trends across intakes. Given the biologic plausibility of a protective effect for fiber and $n-3$ PUFA, the robust results from preclinical models, and the mixed results in observational studies, controlled feeding trials with standardized intakes and consideration of the potential impact of the gut microbiome are urgently needed.

Acknowledgments: We acknowledge the WHI Investigator Group, short list: Program Office: (National Heart, Lung, and Blood Institute, Bethesda, Maryland); Jacques Rossouw, Shari Ludlam, Dale Burwen, Joan McGowan, Leslie Ford, and Nancy Geller; Clinical Coordinating Center: (Fred Hutchinson Cancer Research Center, Seattle, WA, USA) Garnet Anderson, Ross Prentice, Andrea LaCroix, and Charles Kooperberg; Investigators and Academic Centers: (Brigham and Women's Hospital, Harvard Medical School, Boston, MA, USA) JoAnn E. Manson; (MedStar Health Research Institute/Howard University, Washington, DC, USA) Barbara V. Howard; (Stanford Prevention Research Center, Stanford, CA, USA) Marcia L. Stefanick; (The Ohio State University, Columbus, OH, USA) Rebecca Jackson; (University of Arizona, Tucson/Phoenix, AZ, USA) Cynthia A. Thomson; (University at Buffalo, Buffalo, NY, USA) Jean Wactawski-Wende; (University of Florida, Gainesville/Jacksonville, FL, USA) Marian Limacher; (University of Iowa, Iowa City/Davenport, IA, USA) Robert Wallace; (University of Pittsburgh, Pittsburgh, PA, USA) Lewis Kuller; (Wake Forest University School of Medicine, Winston-Salem, NC, USA) Sally Shumaker. Women's Health Initiative Memory Study: (Wake Forest University School of Medicine, Winston-Salem, NC, USA) Sally Shumaker; WHI is supported by National Heart, Lung, and Blood Institute, National Institutes of Health, U.S. Department of Health and Human Services through contracts, HHSN268201100046C (Fred Hutch), HHSN268201100001C (SUNY Buffalo), HHSN268201100002C (The Ohio State University), HHSN268201100003C (Stanford), HHSN268201100004C (Wake Forest), and HHSN271201100004C (WHI Memory Study), and grants P30 CA015704, R35 CA197707, and T32 CA09168.

Author Contributions: Author contributions: S.L.N., J.W.L., M.L.N., S.A.A.B., T.-Y.D.C., L.F.T. and R.S.C. conceived the study; S.L.N., T.-Y.D.C. and M.L.N. conducted the data analysis; S.L.N., M.L.N., T.-Y.D.C., R.S.C. and J.W.L. interpreted the results; S.L.N. wrote the manuscript; M.L.N., J.W.L., R.S.C., T.-Y.D.C., L.F.T., J.M.S., L.S., J.A.M., I.K. and S.A.A.B. critically revised the manuscript.

Conflicts of Interest: The authors declare no conflict of interest.

\section{References}

1. American Cancer Society. Cancer Facts E Figures 2016; American Cancer Society: Atlanta, GA, USA, 2016.

2. World Cancer Research Fund. Food, Nutrition, Physical Activity, and the Prevention of Cancer: A Global Perspective; American Institute for Cancer Research: Washington, DC, USA, 2007.

3. Perez-Cueto, F.J.; Verbeke, W. Consumer implications of the WCRF's permanent update on colorectal cancer. Meat. Sci. 2012, 90, 977-978. [CrossRef] [PubMed] 
4. Ben, Q.; Sun, Y.; Chai, R.; Qian, A.; Xu, B.; Yuan, Y. Dietary fiber intake reduces risk for colorectal adenoma: A meta-analysis. Gastroenterology 2014, 146, 689-699. [CrossRef] [PubMed]

5. Michels, K.B.; Fuchs, C.S.; Giovannucci, E.; Colditz, G.A.; Hunter, D.J.; Stampfer, M.J.; Willett, W.C. Fiber intake and incidence of colorectal cancer among 76,947 women and 47,279 men. Cancer Epidemiol. Biomark. Prev. 2005, 14, 842-849. [CrossRef] [PubMed]

6. Murphy, N.; Norat, T.; Ferrari, P.; Jenab, M.; Bueno-de-Mesquita, B.; Skeie, G.; Dahm, C.C.; Overvad, K.; Olsen, A.; Tjonneland, A.; et al. Dietary fibre intake and risks of cancers of the colon and rectum in the european prospective investigation into cancer and nutrition (epic). PLoS ONE 2012, 7, e39361. [CrossRef] [PubMed]

7. Gerber, M. Omega-3 fatty acids and cancers: A systematic update review of epidemiological studies. Br. J. Nutr. 2012, 107, S228-S239. [CrossRef] [PubMed]

8. Kunzmann, A.T.; Coleman, H.G.; Huang, W.Y.; Kitahara, C.M.; Cantwell, M.M.; Berndt, S.I. Dietary fiber intake and risk of colorectal cancer and incident and recurrent adenoma in the prostate, lung, colorectal, and ovarian cancer screening trial. Am. J. Clin. Nutr. 2015, 102, 881-890. [CrossRef] [PubMed]

9. Wakai, K.; Date, C.; Fukui, M.; Tamakoshi, K.; Watanabe, Y.; Hayakawa, N.; Kojima, M.; Kawado, M.; Suzuki, K.; Hashimoto, S.; et al. Dietary fiber and risk of colorectal cancer in the japan collaborative cohort study. Cancer Epidemiol. Biomark. Prev. 2007, 16, 668-675. [CrossRef] [PubMed]

10. Uchida, K.; Kono, S.; Yin, G.; Toyomura, K.; Nagano, J.; Mizoue, T.; Mibu, R.; Tanaka, M.; Kakeji, Y.; Maehara, Y.; et al. Dietary fiber, source foods and colorectal cancer risk: The fukuoka colorectal cancer study. Scand. J. Gastroenterol. 2010, 45, 1223-1231. [CrossRef] [PubMed]

11. Park, Y.; Hunter, D.J.; Spiegelman, D.; Bergkvist, L.; Berrino, F.; van den Brandt, P.A.; Buring, J.E.; Colditz, G.A.; Freudenheim, J.L.; Fuchs, C.S.; et al. Dietary fiber intake and risk of colorectal cancer: A pooled analysis of prospective cohort studies. JAMA 2005, 294, 2849-2857. [CrossRef] [PubMed]

12. Willett, W.C.; Stampfer, M.J.; Colditz, G.A.; Rosner, B.A.; Speizer, F.E. Relation of meat, fat, and fiber intake to the risk of colon cancer in a prospective-study among women. N. Engl. J. Med. 1990, 323, 1664-1672. [CrossRef] [PubMed]

13. Schatzkin, A.; Mouw, T.; Park, Y.; Subar, A.F.; Kipnis, V.; Hollenbeck, A.; Leitzmann, M.F.; Thompson, F.E. Dietary fiber and whole-grain consumption in relation to colorectal cancer in the nih-aarp diet and health study. Am. J. Clin. Nutr. 2007, 85, 1353-1360. [PubMed]

14. Fuchs, C.S.; Giovannucci, E.L.; Colditz, G.A.; Hunter, D.J.; Stampfer, M.J.; Rosner, B.; Speizer, F.E.; Willett, W.C. Dietary fiber and the risk of colorectal cancer and adenoma in women. N. Engl. J. Med. 1999, 340, 169-176. [CrossRef] [PubMed]

15. MacLean, C.H.; Newberry, S.J.; Mojica, W.A.; Khanna, P.; Issa, A.M.; Suttorp, M.J.; Lim, Y.W.; Traina, S.B.; Hilton, L.; Garland, R.; et al. Effects of omega-3 fatty acids on cancer risk: A systematic review. JAMA 2006, 295, 403-415. [CrossRef] [PubMed]

16. Daniel, C.R.; McCullough, M.L.; Patel, R.C.; Jacobs, E.J.; Flanders, W.D.; Thun, M.J.; Calle, E.E. Dietary intake of omega- 6 and omega-3 fatty acids and risk of colorectal cancer in a prospective cohort of US men and women. Cancer Epidemiol. Biomark. Prev. 2009, 18, 516-525. [CrossRef] [PubMed]

17. Kantor, E.D.; Lampe, J.W.; Peters, U.; Vaughan, T.L.; White, E. Long-chain omega-3 polyunsaturated fatty acid intake and risk of colorectal cancer. Nutr. Cancer 2014, 66, 716-727. [CrossRef] [PubMed]

18. Ward, H.A.; Norat, T.; Overvad, K.; Dahm, C.C.; Bueno-de-Mesquita, H.B.; Jenab, M.; Fedirko, V.; van Duijnhoven, F.J.; Skeie, G.; Romaguera-Bosch, D.; et al. Pre-diagnostic meat and fibre intakes in relation to colorectal cancer survival in the european prospective investigation into cancer and nutrition. Br. J. Nutr. 2016, 116, 316-325. [CrossRef] [PubMed]

19. Liu, L.; Wang, S.; Liu, J. Fiber consumption and all-cause, cardiovascular, and cancer mortalities: A systematic review and meta-analysis of cohort studies. Mol. Nutr. Food Res. 2015, 59, 139-146. [CrossRef] [PubMed]

20. Hajishafiee, M.; Saneei, P.; Benisi-Kohansal, S.; Esmaillzadeh, A. Cereal fibre intake and risk of mortality from all causes, cvd, cancer and inflammatory diseases: A systematic review and meta-analysis of prospective cohort studies. Br. J. Nutr. 2016, 116, 343-352. [CrossRef] [PubMed]

21. Song, M.; Chan, A.T.; Fuchs, C.S.; Ogino, S.; Hu, F.B.; Mozaffarian, D.; Ma, J.; Willett, W.C.; Giovannucci, E.L.; $\mathrm{Wu}, \mathrm{K}$. Dietary intake of fish, omega-3 and omega- 6 fatty acids and risk of colorectal cancer: A prospective study in U.S. Men and women. Int. J. Cancer 2014, 135, 2413-2423. [CrossRef] [PubMed] 
22. Kraja, B.; Muka, T.; Ruiter, R.; de Keyser, C.E.; Hofman, A.; Franco, O.H.; Stricker, B.H.; Kiefte-de Jong, J.C. Dietary fiber intake modifies the positive association between $n-3$ pufa intake and colorectal cancer risk in a Caucasian population. J. Nutr. 2015, 145, 1709-1716. [CrossRef] [PubMed]

23. Trock, B.; Lanza, E.; Greenwald, P. Dietary fiber, vegetables, and colon cancer: Critical review and meta-analyses of the epidemiologic evidence. J. Natl. Cancer Inst. 1990, 82, 650-661. [CrossRef] [PubMed]

24. Vargas, A.J.; Neuhouser, M.L.; George, S.M.; Thomson, C.A.; Ho, G.Y.; Rohan, T.E.; Kato, I.; Nassir, R.; Hou, L.; Manson, J.E. Diet quality and colorectal cancer risk in the women's health initiative observational study. Am. J. Epidemiol. 2016, 184, 23-32. [CrossRef] [PubMed]

25. Makarem, N.; Nicholson, J.M.; Bandera, E.V.; McKeown, N.M.; Parekh, N. Consumption of whole grains and cereal fiber in relation to cancer risk: A systematic review of longitudinal studies. Nutr. Rev. 2016, 74, 353-373. [CrossRef] [PubMed]

26. Aune, D.; Chan, D.S.; Lau, R.; Vieira, R.; Greenwood, D.C.; Kampman, E.; Norat, T. Dietary fibre, whole grains, and risk of colorectal cancer: Systematic review and dose-response meta-analysis of prospective studies. BMJ 2011, 343, d6617. [CrossRef] [PubMed]

27. Aune, D.; Lau, R.; Chan, D.S.; Vieira, R.; Greenwood, D.C.; Kampman, E.; Norat, T. Nonlinear reduction in risk for colorectal cancer by fruit and vegetable intake based on meta-analysis of prospective studies. Gastroenterology 2011, 141, 106-118. [CrossRef] [PubMed]

28. Beresford, S.A.; Johnson, K.C.; Ritenbaugh, C.; Lasser, N.L.; Snetselaar, L.G.; Black, H.R.; Anderson, G.L.; Assaf, A.R.; Bassford, T.; Bowen, D.; et al. Low-fat dietary pattern and risk of colorectal cancer: The women's health initiative randomized controlled dietary modification trial. JAMA 2006, 295, 643-654. [CrossRef] [PubMed]

29. Donohoe, D.R.; Bultman, S.J. Metaboloepigenetics: Interrelationships between energy metabolism and epigenetic control of gene expression. J. Cell. Physiol. 2012, 227, 3169-3177. [CrossRef] [PubMed]

30. Donohoe, D.R.; Garge, N.; Zhang, X.X.; Sun, W.; O'Connell, T.M.; Bunger, M.K.; Bultman, S.J. The microbiome and butyrate regulate energy metabolism and autophagy in the mammalian colon. Cell Metab. 2011, 13, 517-526. [CrossRef] [PubMed]

31. Kolar, S.; Barhoumi, R.; Jones, C.K.; Wesley, J.; Lupton, J.R.; Fan, Y.Y.; Chapkin, R.S. Interactive effects of fatty acid and butyrate-induced mitochondrial $\mathrm{Ca}(2)(+)$ loading and apoptosis in colonocytes. Cancer 2011, 117, 5294-5303. [CrossRef] [PubMed]

32. Kansal, S.; Negi, A.K.; Bhatnagar, A.; Agnihotri, N. Ras signaling pathway in the chemopreventive action of different ratios of fish oil and corn oil in experimentally induced colon carcinogenesis. Nutr. Cancer 2012, 64, 559-568. [CrossRef] [PubMed]

33. Kolar, S.S.; Barhoumi, R.; Callaway, E.S.; Fan, Y.Y.; Wang, N.; Lupton, J.R.; Chapkin, R.S. Synergy between docosahexaenoic acid and butyrate elicits $\mathrm{p} 53$-independent apoptosis via mitochondrial $\mathrm{Ca}(2+)$ accumulation in colonocytes. Am. J. Physiol. Gastrointest. Liver Physiol. 2007, 293, G935-G943. [CrossRef] [PubMed]

34. Kolar, S.S.; Barhoumi, R.; Lupton, J.R.; Chapkin, R.S. Docosahexaenoic acid and butyrate synergistically induce colonocyte apoptosis by enhancing mitochondrial Ca2+ accumulation. Cancer Res. 2007, 67, 5561-5568. [CrossRef] [PubMed]

35. Ng, Y.; Barhoumi, R.; Tjalkens, R.B.; Fan, Y.Y.; Kolar, S.; Wang, N.; Lupton, J.R.; Chapkin, R.S. The role of docosahexaenoic acid in mediating mitochondrial membrane lipid oxidation and apoptosis in colonocytes. Carcinogenesis 2005, 26, 1914-1921. [CrossRef] [PubMed]

36. Hooda, S.; Boler, B.M.; Serao, M.C.; Brulc, J.M.; Staeger, M.A.; Boileau, T.W.; Dowd, S.E.; Fahey, G.C., Jr.; Swanson, K.S. 454 pyrosequencing reveals a shift in fecal microbiota of healthy adult men consuming polydextrose or soluble corn fiber. J. Nutr. 2012, 142, 1259-1265. [CrossRef] [PubMed]

37. Ross, A.B.; Bruce, S.J.; Blondel-Lubrano, A.; Oguey-Araymon, S.; Beaumont, M.; Bourgeois, A.; Nielsen-Moennoz, C.; Vigo, M.; Fay, L.B.; Kochhar, S.; et al. A whole-grain cereal-rich diet increases plasma betaine, and tends to decrease total and ldl-cholesterol compared with a refined-grain diet in healthy subjects. Br. J. Nutr. 2011, 105, 1492-1502. [CrossRef] [PubMed]

38. Costabile, A.; Klinder, A.; Fava, F.; Napolitano, A.; Fogliano, V.; Leonard, C.; Gibson, G.R.; Tuohy, K.M. Whole-grain wheat breakfast cereal has a prebiotic effect on the human gut microbiota: A double-blind, placebo-controlled, crossover study. Br. J. Nutr. 2008, 99, 110-120. [CrossRef] [PubMed] 
39. Finley, J.W.; Burrell, J.B.; Reeves, P.G. Pinto bean consumption changes scfa profiles in fecal fermentations, bacterial populations of the lower bowel, and lipid profiles in blood of humans. J. Nutr. 2007, 137, 2391-2398. [PubMed]

40. Smith, S.C.; Choy, R.; Johnson, S.K.; Hall, R.S.; Wildeboer-Veloo, A.C.; Welling, G.W. Lupin kernel fiber consumption modifies fecal microbiota in healthy men as determined by rrna gene fluorescent in situ hybridization. Eur. J. Nutr. 2006, 45, 335-341. [CrossRef] [PubMed]

41. Johnson, S.K.; Chua, V.; Hall, R.S.; Baxter, A.L. Lupin kernel fibre foods improve bowel function and beneficially modify some putative faecal risk factors for colon cancer in men. Br. J. Nutr. 2006, 95, 372-378. [CrossRef] [PubMed]

42. Tuohy, K.M.; Kolida, S.; Lustenberger, A.M.; Gibson, G.R. The prebiotic effects of biscuits containing partially hydrolysed guar gum and fructo-oligosaccharides-A human volunteer study. Br. J. Nutr. 2001, 86, 341-348. [CrossRef] [PubMed]

43. Hylla, S.; Gostner, A.; Dusel, G.; Anger, H.; Bartram, H.P.; Christl, S.U.; Kasper, H.; Scheppach, W. Effects of resistant starch on the colon in healthy volunteers: Possible implications for cancer prevention. Am. J. Clin. Nutr. 1998, 67, 136-142. [PubMed]

44. Arumugam, M.; Raes, J.; Pelletier, E.; Le Paslier, D.; Yamada, T.; Mende, D.R.; Fernandes, G.R.; Tap, J.; Bruls, T.; Batto, J.M.; et al. Enterotypes of the human gut microbiome. Nature 2011, 473, 174-180. [CrossRef] [PubMed]

45. Faust, K.; Raes, J. Microbial interactions: From networks to models. Nat. Rev. Microbiol. 2012, 10, 538-550. [CrossRef] [PubMed]

46. Faust, K.; Sathirapongsasuti, J.F.; Izard, J.; Segata, N.; Gevers, D.; Raes, J.; Huttenhower, C. Microbial co-occurrence relationships in the human microbiome. PLoS Comput. Biol. 2012, 8, e1002606. [CrossRef] [PubMed]

47. Lozupone, C.; Faust, K.; Raes, J.; Faith, J.J.; Frank, D.N.; Zaneveld, J.; Gordon, J.I.; Knight, R. Identifying genomic and metabolic features that can underline early successional and opportunistic lifestyles of human gut symbionts. Genome Res. 2012, 22, 1974-1984. [CrossRef] [PubMed]

48. Bolca, S.; van de Wiele, T.; Possemiers, S. Gut metabotypes govern health effects of dietary polyphenols. Curr. Opin. Biotechnol. 2013, 24, 220-225. [CrossRef] [PubMed]

49. Heinzmann, S.S.; Merrifield, C.A.; Rezzi, S.; Kochhar, S.; Lindon, J.C.; Holmes, E.; Nicholson, J.K. Stability and robustness of human metabolic phenotypes in response to sequential food challenges. J. Proteome Res. 2012, 11, 643-655. [CrossRef] [PubMed]

50. Wang, T.; Cai, G.; Qiu, Y.; Fei, N.; Zhang, M.; Pang, X.; Jia, W.; Cai, S.; Zhao, L. Structural segregation of gut microbiota between colorectal cancer patients and healthy volunteers. ISME J. 2012, 6, 320-329. [CrossRef] [PubMed]

51. Weir, T.L.; Manter, D.K.; Sheflin, A.M.; Barnett, B.A.; Heuberger, A.L.; Ryan, E.P. Stool microbiome and metabolome differences between colorectal cancer patients and healthy adults. PLOS ONE 2013, 8, e70803. [CrossRef] [PubMed]

52. Wu, N.; Yang, X.; Zhang, R.; Li, J.; Xiao, X.; Hu, Y.; Chen, Y.; Yang, F.; Lu, N.; Wang, Z.; et al. Dysbiosis signature of fecal microbiota in colorectal cancer patients. Microb. Ecol. 2013, 66, 462-470. [CrossRef] [PubMed]

53. Simopoulos, A.P. Importance of the omega-6/omega-3 balance in health and disease: Evolutionary aspects of diet. World Rev. Nutr. Diet. 2011, 102, 10-21. [PubMed]

54. Strobel, C.; Jahreis, G.; Kuhnt, K. Survey of n-3 and n-6 polyunsaturated fatty acids in fish and fish products. Lipids Health Dis. 2012, 11, 144. [CrossRef] [PubMed]

55. Skender, B.; Hyrslova Vaculova, A.; Hofmanova, J. Docosahexaenoic fatty acid (dha) in the regulation of colon cell growth and cell death: A review. Biomed. Pap. Med. Fac. Univ. Palacky Olomouc Czech. Repub. 2012, 156, 186-199. [CrossRef] [PubMed]

56. Azer, S.A. Overview of molecular pathways in inflammatory bowel disease associated with colorectal cancer development. Eur. J. Gastroenterol. Hepatol. 2012, 25, 271-281. [CrossRef] [PubMed]

57. Cockbain, A.J.; Toogood, G.J.; Hull, M.A. Omega-3 polyunsaturated fatty acids for the treatment and prevention of colorectal cancer. Gut 2012, 61, 135-149. [CrossRef] [PubMed]

58. Chang, W.C.; Chapkin, R.S.; Lupton, J.R. Predictive value of proliferation, differentiation and apoptosis as intermediate markers for colon tumorigenesis. Carcinogenesis 1997, 18, 721-730. [CrossRef] [PubMed] 
59. Sanders, L.M.; Henderson, C.E.; Hong, M.Y.; Barhoumi, R.; Burghardt, R.C.; Wang, N.; Spinka, C.M.; Carroll, R.J.; Turner, N.D.; Chapkin, R.S.; et al. An increase in reactive oxygen species by dietary fish oil coupled with the attenuation of antioxidant defenses by dietary pectin enhances rat colonocyte apoptosis. J. Nutr. 2004, 134, 3233-3238. [PubMed]

60. Vanamala, J.; Glagolenko, A.; Yang, P.; Carroll, R.J.; Murphy, M.E.; Newman, R.A.; Ford, J.R.; Braby, L.A.; Chapkin, R.S.; Turner, N.D.; et al. Dietary fish oil and pectin enhance colonocyte apoptosis in part through suppression of ppardelta/pge2 and elevation of pge3. Carcinogenesis 2008, 29, 790-796. [CrossRef] [PubMed]

61. Crim, K.C.; Sanders, L.M.; Hong, M.Y.; Taddeo, S.S.; Turner, N.D.; Chapkin, R.S.; Lupton, J.R. Upregulation of p21waf1/cip1 expression in vivo by butyrate administration can be chemoprotective or chemopromotive depending on the lipid component of the diet. Carcinogenesis 2008, 29, 1415-1420. [CrossRef] [PubMed]

62. Cho, Y.; Kim, H.; Turner, N.D.; Mann, J.C.; Wei, J.; Taddeo, S.S.; Davidson, L.A.; Wang, N.; Vannucci, M.; Carroll, R.J.; et al. A chemoprotective fish oil- and pectin-containing diet temporally alters gene expression profiles in exfoliated rat colonocytes throughout oncogenesis. J. Nutr. 2011, 141, 1029-1035. [CrossRef] [PubMed]

63. The Women's Health Initiative Study Group. Design of the women's health initiative clinical trial and observational study. Control. Clin. Trials 1998, 19, 61-109.

64. Anderson, G.L.; Manson, J.; Wallace, R.; Lund, B.; Hall, D.; Davis, S.; Shumaker, S.; Wang, C.Y.; Stein, E.; Prentice, R.L. Implementation of the women's health initiative study design. Ann. Epidemiol. 2003, 13, S5-S17. [CrossRef]

65. Langer, R.D.; White, E.; Lewis, C.E.; Kotchen, J.M.; Hendrix, S.L.; Trevisan, M. The women's health initiative observational study: Baseline characteristics of participants and reliability of baseline measures. Ann. Epidemiol. 2003, 13, S107-S121. [CrossRef]

66. Hays, J.; Hunt, J.R.; Hubbell, F.A.; Anderson, G.L.; Limacher, M.; Allen, C.; Rossouw, J.E. The women's health initiative recruitment methods and results. Ann. Epidemiol. 2003, 13, S18-S77. [CrossRef]

67. Patterson, R.E.; Kristal, A.R.; Tinker, L.F.; Carter, R.A.; Bolton, M.P.; Agurs-Collins, T. Measurement characteristics of the women's health initiative food frequency questionnaire. Ann. Epidemiol. 1999, 9, 178-187. [CrossRef]

68. Curb, J.D.; McTiernan, A.; Heckbert, S.R.; Kooperberg, C.; Stanford, J.; Nevitt, M.; Johnson, K.C.; Proulx-Burns, L.; Pastore, L.; Criqui, M.; et al. Outcomes ascertainment and adjudication methods in the women's health initiative. Ann. Epidemiol. 2003, 13, S122-S128. [CrossRef]

69. Haggar, F.A.; Boushey, R.P. Colorectal cancer epidemiology: Incidence, mortality, survival, and risk factors. Clin. Colon Rectal Surg. 2009, 22, 191-197. [CrossRef] [PubMed]

70. Edwards, B.K.; Ward, E.; Kohler, B.A.; Eheman, C.; Zauber, A.G.; Anderson, R.N.; Jemal, A.; Schymura, M.J.; Lansdorp-Vogelaar, I.; Seeff, L.C.; et al. Annual report to the nation on the status of cancer, 1975-2006, featuring colorectal cancer trends and impact of interventions (risk factors, screening, and treatment) to reduce future rates. Cancer 2010, 116, 544-573. [CrossRef] [PubMed]

71. National Academy of Sciences-Institute of Medicine. Food and Nutrition Board. Dietary Reference Intakes for Energy, Carbohydrate, Fiber, Fat, Fatty Acids, Cholesterol, Protein, and Amino Acids; National Academy Press: Washington, DC, USA, 2005.

72. American Institute For Cancer Research. Available online: http://www.Aicr.Org/continuous-updateproject/colorectal-cancer.Html (accessed on 4 November 2016).

73. Bingham, S.A. Diet and large bowel cancer. J. R. Soc. Med. 1990, 83, 420-422. [PubMed]

74. Young, G.P.; Hu, Y.; Le Leu, R.K.; Nyskohus, L. Dietary fibre and colorectal cancer: A model for environment-gene interactions. Mol. Nutr. Food Res. 2005, 49, 571-584. [CrossRef] [PubMed]

75. Slavin, J.L. Dietary fiber and body weight. Nutrition 2005, 21, 411-418. [CrossRef] [PubMed]

76. Donohoe, D.R.; Collins, L.B.; Wali, A.; Bigler, R.; Sun, W.; Bultman, S.J. The warburg effect dictates the mechanism of butyrate-mediated histone acetylation and cell proliferation. Mol. Cell 2012, 48, 612-626. [CrossRef] [PubMed]

77. Bultman, S.J. Molecular pathways: Gene-environment interactions regulating dietary fiber induction of proliferation and apoptosis via butyrate for cancer prevention. Clin. Cancer Res. 2014, 20, 799-803. [CrossRef] [PubMed] 
78. Triff, K.; Kim, E.; Chapkin, R.S. Chemoprotective epigenetic mechanisms in a colorectal cancer model: Modulation by n-3 pufa in combination with fermentable fiber. Curr. Pharmacol. Rep. 2015, 1, 11-20. [CrossRef] [PubMed]

79. Chapkin, R.S.; Seo, J.; McMurray, D.N.; Lupton, J.R. Mechanisms by which docosahexaenoic acid and related fatty acids reduce colon cancer risk and inflammatory disorders of the intestine. Chem. Phys. Lipids 2008, 153, 14-23. [CrossRef] [PubMed]

80. Levi, F.; Pasche, C.; Lucchini, F.; la Vecchia, C. Dietary fibre and the risk of colorectal cancer. Eur. J. Cancer 2001, 37, 2091-2096. [CrossRef]

81. Freudenheim, J.L.; Graham, S.; Horvath, P.J.; Marshall, J.R.; Haughey, B.P.; Wilkinson, G. Risks associated with source of fiber and fiber components in cancer of the colon and rectum. Cancer Res. 1990, 50, 3295-3300. [PubMed]

82. Le Marchand, L.; Hankin, J.H.; Wilkens, L.R.; Kolonel, L.N.; Englyst, H.N.; Lyu, L.C. Dietary fiber and colorectal cancer risk. Epidemiology 1997, 8, 658-665. [CrossRef] [PubMed]

83. Negri, E.; Franceschi, S.; Parpinel, M.; La Vecchia, C. Fiber intake and risk of colorectal cancer. Cancer Epidemiol. Biomark. Prev. 1998, 7, 667-671.

84. Turk, H.F.; Monk, J.M.; Fan, Y.Y.; Callaway, E.S.; Weeks, B.; Chapkin, R.S. Inhibitory effects of omega-3 fatty acids on injury-induced epidermal growth factor receptor transactivation contribute to delayed wound healing. Am. J. Physiol. Cell Physiol. 2013, 304, C905-C917. [CrossRef] [PubMed]

85. Larsson, S.C.; Kumlin, M.; Ingelman-Sundberg, M.; Wolk, A. Dietary long-chain $n-3$ fatty acids for the prevention of cancer: A review of potential mechanisms. Am. J. Clin. Nutr. 2004, 79, 935-945. [PubMed]

86. Wu, S.; Feng, B.; Li, K.; Zhu, X.; Liang, S.; Liu, X.; Han, S.; Wang, B.; Wu, K.; Miao, D.; et al. Fish consumption and colorectal cancer risk in humans: A systematic review and meta-analysis. Am. J. Med. 2012, 125, 551-559. [CrossRef] [PubMed]

87. Geelen, A.; Schouten, J.M.; Kamphuis, C.; Stam, B.E.; Burema, J.; Renkema, J.M.; Bakker, E.J.; van't Veer, P.; Kampman, E. Fish consumption, $n-3$ fatty acids, and colorectal cancer: A meta-analysis of prospective cohort studies. Am. J. Epidemiol. 2007, 166, 1116-1125. [CrossRef] [PubMed]

88. Song, M.; Zhang, X.; Meyerhardt, J.A.; Giovannucci, E.L.; Ogino, S.; Fuchs, C.S.; Chan, A.T. Marine omega-3 polyunsaturated fatty acid intake and survival after colorectal cancer diagnosis. Gut 2016. [CrossRef] [PubMed]

89. Vannice, G.; Rasmussen, H. Position of the academy of nutrition and dietetics: Dietary fatty acids for healthy adults. J. Acad. Nutr. Diet. 2014, 114, 136-153. [CrossRef] [PubMed]

90. Jiang, Y.H.; Lupton, J.R.; Chapkin, R.S. Dietary fat and fiber modulate the effect of carcinogen on colonic protein kinase c lambda expression in rats. J. Nutr. 1997, 127, 1938-1943. [PubMed]

91. Fan, Y.Y.; Ran, Q.; Toyokuni, S.; Okazaki, Y.; Callaway, E.S.; Lupton, J.R.; Chapkin, R.S. Dietary fish oil promotes colonic apoptosis and mitochondrial proton leak in oxidatively stressed mice. Cancer Prev. Res. 2011, 4, 1267-1274. [CrossRef] [PubMed]

92. Orlich, M.J.; Singh, P.N.; Sabate, J.; Fan, J.; Sveen, L.; Bennett, H.; Knutsen, S.F.; Beeson, W.L.; Jaceldo-Siegl, K.; Butler, T.L.; et al. Vegetarian dietary patterns and the risk of colorectal cancers. JAMA Intern. Med. 2015, 175, 767-776. [CrossRef] [PubMed]

93. O’Keefe, S.J.; Li, J.V.; Lahti, L.; Ou, J.; Carbonero, F.; Mohammed, K.; Posma, J.M.; Kinross, J.; Wahl, E.; Ruder, E.; et al. Fat, fibre and cancer risk in African americans and rural Africans. Nat. Commun. 2015, 6, 6342. [CrossRef] [PubMed]

94. Kato, I.; Majumdar, A.P.; Land, S.J.; Barnholtz-Sloan, J.S.; Severson, R.K. Dietary fatty acids, luminal modifiers, and risk of colorectal cancer. Int. J. Cancer 2010, 127, 942-951. [CrossRef] [PubMed]

95. US Department of Agriculture, Agriculture Research Services. Nutrient Intakes from Food: Mean Amounts Consumed per Individual, by Gender and Age. Available online: http://www.ars.usda.gov/ba/bhnrc/fsrg (accessed on 4 November 2016).

96. Kristal, A.R.; Shattuck, A.L.; Williams, A.E. Food Frequency Questionnaires for Diet Intervention Research. In Proceedings of the 17th National Nutrient Databank Conference, Baltimore, MD, USA, 7-10 June 1992.

97. Satia-Abouta, J.; Kristal, A.R.; Patterson, R.E.; Littman, A.J.; Stratton, K.L.; White, E. Dietary supplement use and medical conditions: The vital study. Am. J. Prev. Med. 2003, 24, 43-51. [CrossRef] 
98. Fasano, E.; Serini, S.; Cittadini, A.; Calviello, G. Long-chain n-3 pufa against breast and prostate cancer: Which are the appropriate doses for intervention studies in animals and humans? Crit. Rev. Food Sci. Nutr. 2015. [CrossRef] [PubMed]

99. Vece, M.M.; Agnoli, C.; Grioni, S.; Sieri, S.; Pala, V.; Pellegrini, N.; Frasca, G.; Tumino, R.; Mattiello, A.; Panico, S.; et al. Dietary total antioxidant capacity and colorectal cancer in the italian epic cohort. PLoS ONE 2015, 10, e0142995. [CrossRef] [PubMed]

100. La Vecchia, C.; Decarli, A.; Serafini, M.; Parpinel, M.; Bellocco, R.; Galeone, C.; Bosetti, C.; Zucchetto, A.; Polesel, J.; Lagiou, P.; et al. Dietary total antioxidant capacity and colorectal cancer: A large case-control study in italy. Int. J. Cancer 2013, 133, 1447-1451. [CrossRef] [PubMed]

101. Bjelakovic, G.; Nikolova, D.; Simonetti, R.G.; Gluud, C. Antioxidant supplements for prevention of gastrointestinal cancers: A systematic review and meta-analysis. Lancet 2004, 364, 1219-1228. [CrossRef]

(C) 2016 by the authors; licensee MDPI, Basel, Switzerland. This article is an open access article distributed under the terms and conditions of the Creative Commons Attribution (CC-BY) license (http:/ / creativecommons.org/licenses/by/4.0/). 